\title{
Stories Untold: The street children of Chow Kit - An architectural intervention
}

\author{
Anniz Fazli Ibrahim Bajunid, Mohamad Yusuf Aliaas, Ramli Abdullah \\ Faculty of Architecture, Planning and Surveying, \\ Universiti Teknologi MARA, Malaysia \\ toanniz@gmail.com
}

\begin{abstract}
Chow Kit Road, a busy shopping sanctuary flourishes with economic activities with more than 500 'street children' roaming and living off the streets. These children have been ignored, and much of their life challenges remain unaddressed. This conceptual paper initiates an educational discussion in relation to their environment with a specific architectural design solution. The intervention infuses concepts formed through in-depth interviews with the street children as well as their caretakers. Unobstructed observations were engaged in ensuring the reliability of the data apart from literature reviews and case studies. Issues of education and place of belonging are postulated through an architectural perspective. This study suggests architectural initiatives in contributing to the social agenda of physical urban renewal.
\end{abstract}

Keywords Street Children, Architecture, Learning Centre, Chow Kit Road

eISSN ISSN 2514-751X @ 2018. The Authors. Published for AMER ABRA cE-Bs by e-International Publishing House, Ltd., UK. This is an open-access article under the CC BY-NC-ND license (http://creativecommons.org/licenses/by-nc-nd/4.0/). Peer-review under responsibility of AMER (Association of Malaysian Environment-Behaviour Researchers), ABRA (Association of Behavioural Researchers on Asians) and $c E-B s$ (Centre for Environment-Behaviour Studies), Faculty of Architecture, Planning \& Surveying, Universiti Teknologi MARA, Malaysia.

DOI: https://doi.org/10.21834/aje-bs.v3i6.246 


\subsection{Introduction}

Streetchildren are children in the range from infants to 18 years of age facing various, critical social problems. They were exposed to negative social upbringing either accidentally or have been forced into these predicaments. These challenges are especially evident in the cases of children with undocumented birth certificate. The lack of documentation excludes them from receiving social benefits from the relevant authorities as they are not recorded as a registered citizen (Singh, 2007). Without birth certificates, the authorities' cannot accurately verify and differentiate between local orphans from those of illegal immigrants, refugees or asylum seekers. This issue of identity dysfunction extends beyond orphans to include lost and trafficked children who were brought in from many different areas across the world either as sex slaves or cheap force labour (Paradigm Shift Project, 2010). Other children defined as street children also include those with HIV and AIDS, living with a disability, neglected children from broken families, or children from indigenous families with no documentation.

The objective of this paper concentrates on the study of an architectural intervention proposal for a Kuala Lumpur Street Children Learning Centre. The main area of discussion in this paper is (i) on the behavioural movement of the street children and (ii) how unobstructed observations and in-depth interviews that was conducted, led to a better proposal of spatial design programmes of a learning environment for street children. Literature reviews were undertaken along with two preliminary case studies before observations of the streetchildren's everyday activities, and behaviours were undertaken. In the discussion, a formulation of the data is interpreted in a new architectural building programme that can be inserted into modified existing educational modules, enhancing the learning experiencesand social academic delivery within the proposed learning centre. It is anticipated that the paper will deter further social strain to the country's reputation and restore confidence to NGO's involved in facilitating their initiatives.

\subsection{Literature Review}

Street children have difficulties with authorities as they bear no legal document that justifies their existence. This dilemma automatically denies them of being able to receive basic social rights and privileges (Patt, 2010). However, basic needs such as shelter, food, healthcare and clothing are regularly provided byconcerned non-governmental organisations (NGO's). Basic education on the other hand, is not included in the list. In the Malaysian context, orphanages provide basic education by either sending the orphans to school or through informal education (Bakar, 2010). However, without legal documentation, enrollments are very slim. Without educational activities, the children are left to the streets, fending for themselves with whatever activities they come across.

Kuala Lumpur is home and at the very heart of Malaysia's rapid urban development. Unfortunately, Kuala Lumpur, with Chow Kit Road located in the centre of the city, is also home to a number of street children (Jabatan Kebajikan Masyarakat, 2007). It has recorded a number of street children roaming the surrounding streets (Jabatan Kebajikan Masyarakat, 2008) and is disturbingly increasing (Figure 1). The government's efforts to address this problem seem rather limited at the moment as the initiative are disputed in differences of 
cultural opinions amongst segments of the general community (Singh, 2007). With a number of growing attention and criticisms by international NGO's and media, solving the problem suggests that an immediate action is required. The current lack of stewardship regarding street children are also evident in other societies documented in the literature by (Markusen, 2004) who noted the humanistic destruction and wastage of the human resource within communities which she uniquely calls the 'forgotten places'.

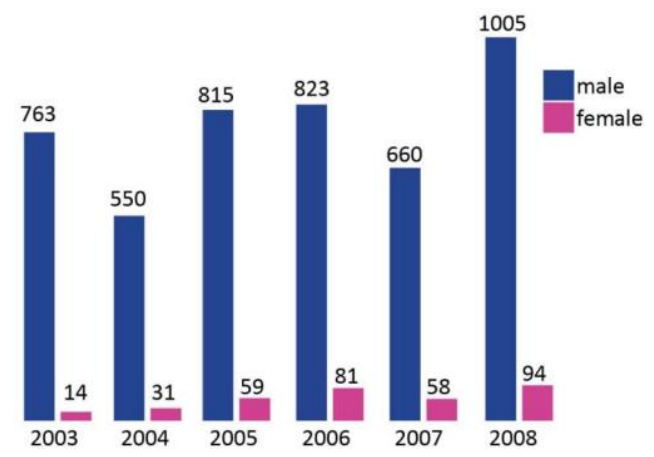

Figure1a:IndicatesGenderDisparityoftheDominant Male Compared To Females

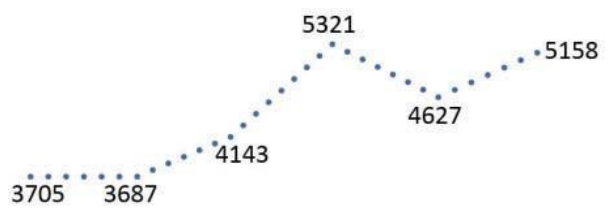

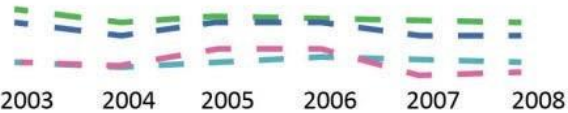

$$
\begin{aligned}
& \text {.....malays } \\
& \text { - chinese } \\
& \text { - - indians } \\
& \text { - - sabah bumiputras } \\
& \text { - sarawak bumiputras }
\end{aligned}
$$

Figure 1b: lllustrates the Acute Predicaments of Various Ethnic Groups Source: (Adapted and redrawn by Author ${ }^{1}$ from Social Welfare Department of Malaysia (www.jkm.gov.my). Presentation boards, Authors.) 
In understanding how children interacts with their learning environment, previous research found that there are areas in the human brain that is related in human movement synchronization. Hannaford (1995), recorded that when more physical muscles are used in a learning process, the more brain power are generated. This thus endorses the necessity of a better spatial arrangement of a classroom rather than the conventional static and rigid seating arrangements (Jenson, 2001). In another research, kinesthetic learning was identified as programmes that are only usually related and limited to extra co-curriculum activities conducted in many conventional schools (Pica, 2010). Activities like singing, dancing, storytelling, and poetry reading, results in quicker response and understanding of the elements and competencies of a certain subject discipline. Drawings, art and sculpture also improves the decision making process, and such activities develop a better result in a more thoughtful and creative child.

This active movement through several of these activities generates a more natural and conducive learning and living environment. It is essential to gather the children's views and their perceived environment to assist in planning (Knowles-Yanez, 2005) which holds many benefits (Frank, 2006), especially in an architectural intervention. Due to diverse learning background, further adjustments and development in kinesthetic learning methods can be incorporated into the design scheme through a series of studies by learning the behaviour of the street children. This will enable a better understanding of the effects of movements that would then be sufficient in generating design interpretations.

Territorial and self-claim spaces are also one of the most important elements that can be used to further the design scheme. Children will subconsciously create their own sense of belonging to a space as well as social spaces with other children (Machemer, Bruch, \& Kuipers, 2008). These spaces are vital for performances of their activities, integral to the kinesthetic learning process.

\subsection{Methodology}

\subsection{In-Depth Interviews and Unobstructed Observations}

In-depth structured interviews were conducted with the only childcare center in Chow Kit and central Kuala Lumpur. Pusat Aktiviti Kanak-kanak Chow Kit is home to almost 156 street children from the locality. There are about 350 children registered, but based on physical limitations and financial constraints, only the keenest was supported. The remainder of the children sadly continues to roam the streets. Information was gathered from the operation's manager and a caretaker. The interviews, among other details allowed assessment of actual availableprogrammesthatare currently conducted in the centre (Figure 2). 

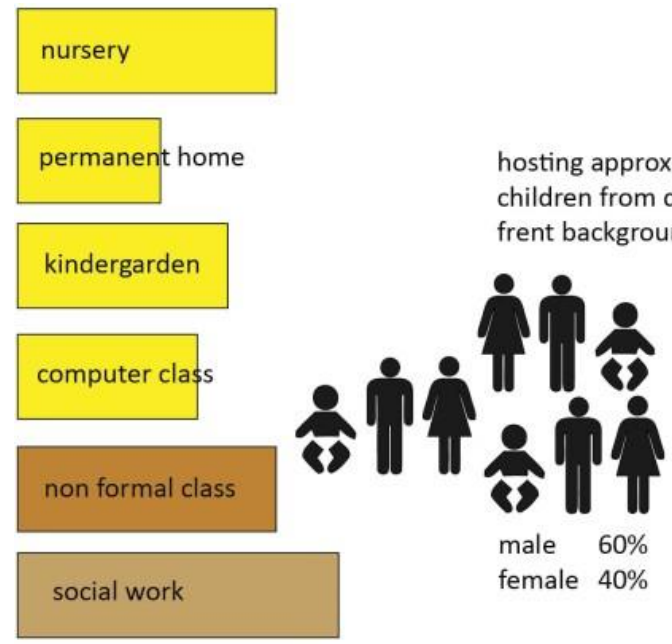

hosting approx 156

children from dif-

frent background

cultural class

music \& art

Figure2: CurrentAvailableProgrammesinPusat Aktiviti Nur Salam in Chow Kit

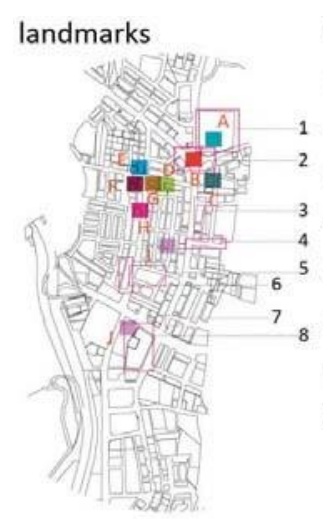

visitors P.O.V local children P.O.V
1. Kuala Lumpur General Hospital
A. Kuala Lumpur General Hospital

2. Chow Kit Station Monorail

B. Chow Kit Station Monorail

3. Cititel Hotel

C. low cost flat Jalan $\mathrm{HJ}$ Hassan

4. Lorong Raja Alang(going to $\mathrm{Kg}$ Baru)

D. Pusat Aktiviti Kanak-kanak Chow Kit

5. KL Metropolitan University

E. KFC Jalan Ipoh/Jalan Putra

6. EON Bank Tower F. low cost flat Jalan Putra

7. Restorant Nasi Kandar terbaek G. 7 eleven Jalan Ipoh

8. Maju Junction Tower $\quad H$. internet cafe

1. Chow Kit Police Station

J. Sekolah Menengah (P) Jalan Batu

Figure 3: Illustration of the Different Nodes Identified by the Street

Children about their Surrounding Environments

Source: (Adapted and redrawn by Authorsfrom Pusat Aktiviti Kanak-kanak Chow Kit.

Presentation boards, Authors.) 
In-depth, informal interviews were also conducted with eight of the street children themselves, independent of their caretakers or guardians. The interviews took place within the children's own setting, in the centre as well as on 'the streets'. This assisted in the informal sessions in order to allow for a genuine response as well as physically illustrate to the interviewer the behavioural nuances. The informal sessions were also conducted in the evening during off peak hours, in a systematic schedule to observe the active movements of the street children. The children who were interviewed gave an invaluable detailed description about their movements, local landmarks that was important to them, as well as nodes that they considered as social 'hanging out' spaces, vital in understanding their behavioural instincts and requirements. Some of the information disclosed their habitual routines and addresses the nature of the spaces that the children are naturally attracted to during their free time, alone and as well as in groups. Their daily activities was mapped and plotted to understand better their behaviour and social needs. It can be surmised that it seems clear that most of the street children did not identify landmarks or nodes that most ordinary people do. It is believed that like most children, their perception and sense of space is further influenced by the modern and technological fabric that surrounds them (Sobchack, 2004), even more so to these urban street children. In a study of street children at railway stations in India, identified that the cognitive maps revealed a number of facts including stress, social identity, place attachment and the utilisation of spaces (Jain, 2010). There seem also an indication of cross-cultural, beliefs and spatial environment variations which needs further independent studies but the differences of the nodal 'hang out' areas of the street children in Chow Kit and of the common public are acknowledged in Figure 3.

\subsection{Case Study}

Two case studies on the programmes of space were conducted to identify the spaces that are required that best suited the street children's learning experience. The gathered data was modified accordingly to fit in the local context of expected habitants, priority of programmes and other subdivisions of spaces required in forming a complete hypothetical program for the learning centre.With considerations of distinct differences in environmental, socio and cultural background, an intense search was conducted for an international example. Among the many close examples for discussion in terms of spatial programming for children was that of Ecole du Parc, which an educational institution in the heart of Paris is. The planning was simple yet practical in terms of space and form configuration (Figure 4). The other most notable feature worth highlighting is its multiple sustainable building policies initiatives, especially in the reduction of energy consumption for sustainable maintenance. 


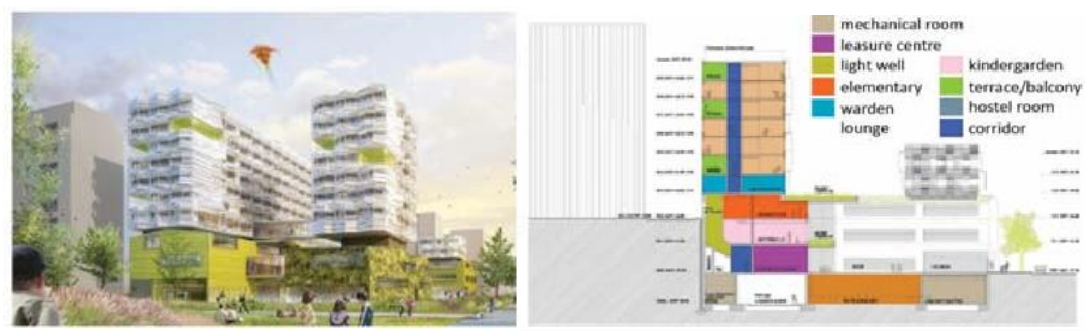

Figure 4: EcoleDuParc,AnEducational Institution with BothLearning and Living Programmes under One Roof

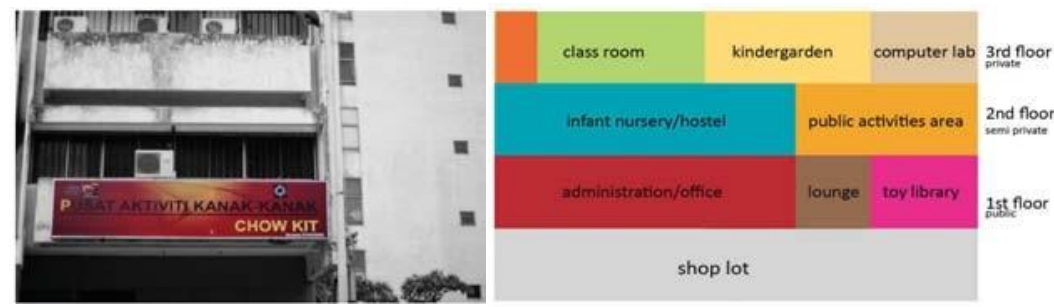

Figure 5: PusatAktivitiKanak-kanakinChowKitRoadanditsCurrent Composition ofProgrammes (Source: Kuala Lumpur Street ChildrenLearning Centre case studies.

Presentation boards, Authors)

The local example of the Pusat Aktiviti Kanak-Kanak Chow Kit is the only childcare centre operating in the Chow Kit area. With limited space, the centre is still able to include a number of educational spaces (Figure 5). Their current program are all fully supported by the corporate sector through their corporate social responsibility endeavours that stimulates social charit works. These small spaces, within its own capacity, provided a platform of justifications of spaces needed within the actual setting of Chow Kit.

\subsection{Results and Discussions}

Whilst there were some analyses made of the various preliminary data that was gathered for the design development processes, for this particular paper, not all aspects of the analysis will be discussed. Nevertheless, the following discussions shall academically pin point the current stage of thoughts and design development.

\subsection{Spatial Concepts}

The spaces designed for children requires a thorough understanding of the anthropometrics as well as types of learning behaviours that best works for them. Most of the street children have 
difficulty in adjusting to the community at large, yet alone a learning environment. In order to resolve this issue, a new learning method is required for the children to be at ease in their learning process. Since the level of formative learning are almost non-existent for most of the street children, a more relaxing and interactive learning setting was administered into the design process shown in Figure 6. This is of course derived from observing their daily behaviours as well.
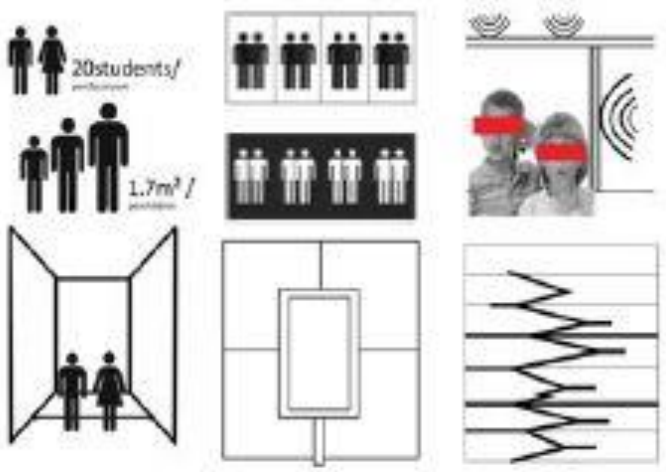

Figure 6): Architectural Intervention Recommendations of a Learning Environment for Street Children.

From Top Left to Right:

Spatial Requirements Per Student, Division of Classrooms According to Specific Traits, Sound Barriers, Width of Corridors and Classrooms, SpaceConfigurations, Vertical Connectivityand Relationships.

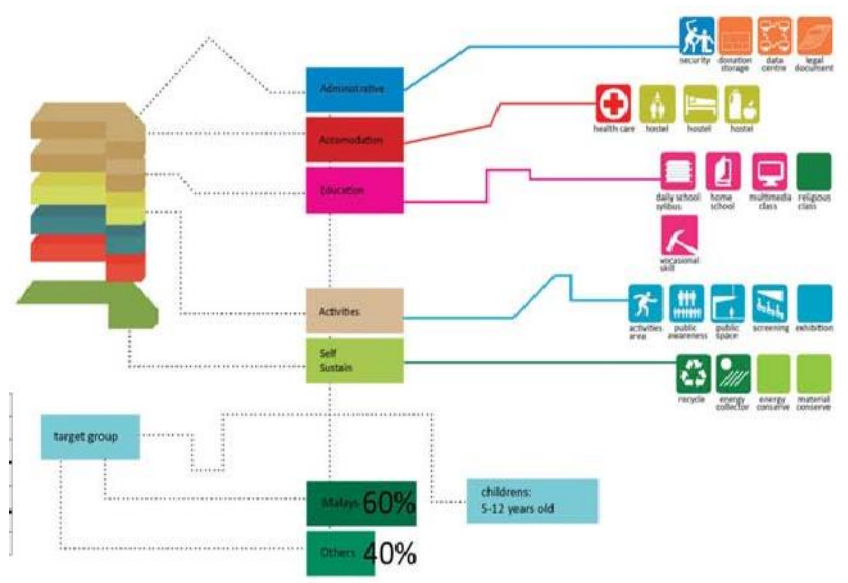

Figure 7: Spatial Programming for the Architectural Intervention of a Street Children Learning Centre (Source: Kuala Lumpur Street Children Learning Centre conceptual diagrams.

Presentation boards, Authors) 


\subsection{Spatial Programming}

\section{Administration and Accommodation}

The administration component of the centre functions as the disciplinary and governing body. All registrations, legal documentation and related activities are managed from here. Security is an essential factor considered, especially with the inconsistent behavioural nature of the street children. It is necessary that a certain discipline is administrated within the freedom and relaxed, learning environment in order to maintain the social integrity of the building.

The basic needs of a shelter for children have to be met, balanced with the inclusion of their everyday activities. Each one of the children will be given a space, shared with three other children. This will allow for common experiences and encourage intermingling. It is anticipated that potentially, positive relationships, higher self-esteems and social communication skills will subconsciously be articulated.

\section{Educational Activities and Self Sustenance}

The national syllabus with a different intermediary method of communication will be administered. This is with minimum formality but through a projected effective spatial delivery. The street children will be taught in a more home oriented style of rational learning. This also includes provisions for vocational learning. A workshop is provided to enhance these vocational and living skills.

Currently, outdoor activities are located throughout the vicinity of Chow Kit Road. In this proposal, the street children will be provided with their own unique spaces for physical activity and safe interaction such as a futsal court, playground and open social spaces to promote safe activities that allow for constructive interaction for both children and visitors. As the centre is only supported by limited funds from NGO's, rentable space for events are included to generate maintenance funds. This is ideal as the surrounding neighbouring buildings lack these facilities. This shall encourage public interest and participation in the recovery of the street children into the community. A sustainable building approach is considered from the conception of design through the delivery of construction to minimize the final costing as well as in the provisions of long term maintenance.

\subsection{Learning Through Interactive Movements}

The following design analysis is a representative pictogram generated from the gathered in-depth interview data, comprehension of the unobstructed observations as well as literature reviews and case studies. It can be described as a logical form of physical, visual and experiential communication based on various elements of the street children behaviours. For example, kinesthetic learners require a different physical setting and allowance of space (Sandhu, 2010), whereas the notion of movements is necessary for children (Jenson, 2001; Pica, 2010) and the stimulation of the Reticular Activating System of the brainstem (Hannaford, 1995). It appears to be contradicting to the conventional format of educational spaces usually designed, but is rather a translation of a new practical method of a fusion of theories, as well as the children's street logic of space and architecture - an attempt at the culmination of 
informal educational permeation of learning activities interweaved within the street children's daily behavioural demeanors

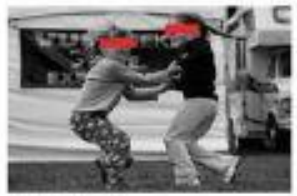

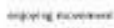

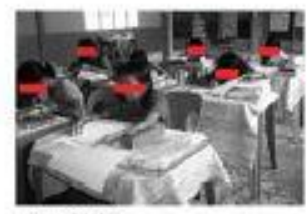

nesentrobs
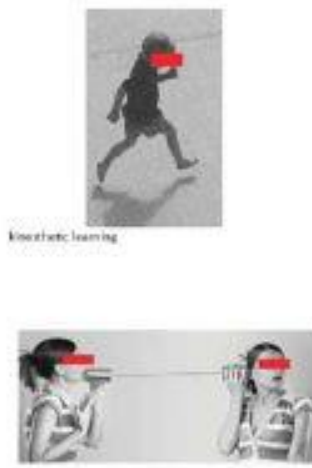

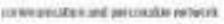

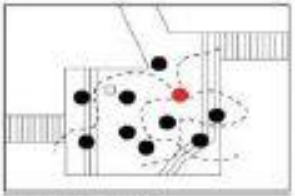

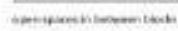
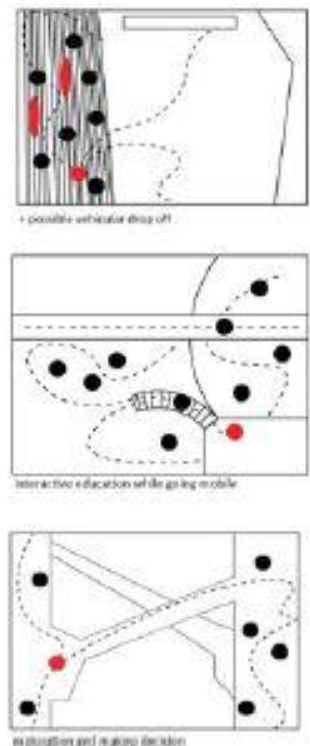
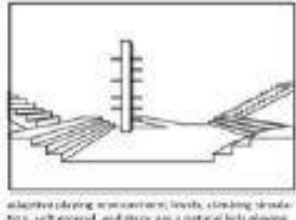

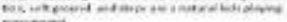

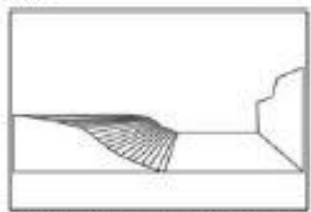

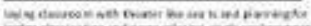
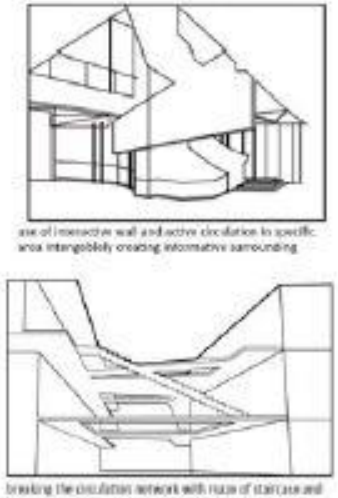

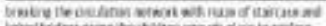

Figure8: Interpretation ofFusionofEvents, MovementsandInformalEducation Based on Behavioural Traits of the Street Children.

From Top Left to Right: Currentlssue(a)-enjoyingmovements, Recommendation(b)-openspacesin between blocks, Expectation (c) - adaptive playing environments; (a) - stressand rigidity,(b)-classroom reinvention, (c)-higher degree of concentration; (a)-kinesthetic learning, (b)-vertical and horizontal spatial interactivity, (c) - informal learning within interactive walls and active circulations; (a) - Communication and network, (b) - visual cues and physical links, (c) exploratory spaces and decision making encouragements.

(Source: Kuala Lumpur Street Children Learning Centre hypothetical building programmes and physical interpretations Pictograms, Authors)

\subsection{Conclusion}

It is important to acknowledge Kuala Lumpur equal to other capitals in its endeavours for economic development that it arrives within its process, certain negative repercussions of urbanism. The public are to be made aware of the issue of the street children of Chow Kit, and 
only then the current predicament of the street children's lives can be changed. The proposal to have a Street Children Learning Centre in the city centre will symbolize the progression of the government towards having youths unblemished from major social problems. It can also be postulated that the inclusion of the street children within the design planning process can prove to be evidently successful in generating a holistic spatial programming for learning (Talen \& Coffindaffer 1999; Knowles-Yanez,2005;Frank,2006). Inthis particular instance, a subgroup of youths within an urban setting - street children - is a positive start but requires further comparative analysis with other similar situations in different countries as advised by Sallis, Prochaska, \& Taylor, (1999). It is also noted that risks exist that this may also turn into a breeding ground for the continuation of the problem with the misinterpretation of a halfway house. However, the intention is addressed at the educational assimilation of living skills, basic acquired knowledge, eastern ideals and practices, whilst imparting social community ethics that are envisioned to negate this malady at its very roots - through the cognitive experiential re- education of the street children. This will also represent a new approach to vocational schools or similar educational institutes in cohesive programming of spaces. Malaysia can be seen as integration of a project truly defining a collective effort of young Malaysians for Malaysia.

\section{Acknowledgement}

This paper is intended as a communication of awareness for the general public. The Authors wishes to record appreciation to all studio personnel for their guidance, ideas and support. Special thanks to Mohd Faizal Abu Bakar for his feedback and information in the early stages of this project. The authors wish to acknowledge an expanded version of this paper available in Procedia - Social and Behavioural Sciences.

\section{References}

Bakar, M. F. (2010, August 15). Pusat Aktiviti Kanak-kanak Chow Kit. (M. Y. Aliaas, Interviewer)

Frank, K. I. (2006). The Potential of Youth Participation in Planning. Journal of Planning Literature, 20(4), 351-371.

Hannaford, C. (1995). Smart Moves: Why Learning is Not All in Your Head. Arlington, VA: Great Ocean Publishers. Jabatan Kebajikan Masyarakat. (2007) dan (2008). Laporan Statistik. Kuala Lumpur.

Jain, U. (2010). Environment of Street Children at Railway Stations in Madhya Pradesh, India. Paper presented at the ASIA / Pasific International Conference on Environment-Behaviour Studies (AicE-Bs 2010), Grand Margherita Hotel, Kuching, Sarawak, Malaysia.

Jenson, E. (2001). Arts with the Brain in Mind. Alexandria: Association for Supervision \& Curriculum Development. Knowles-Yanez, K. L. (2005). Children's Participation in Planning Process. Journal of Planning Literature, 20(1), 314.

Machemer, P. L., Bruch, S. P., \& Kuipers, R. (2008). Comparing Rural and Urban Children's Perception of an Ideal 
Community. Journal of Planning Education and Research, 28, 143-160.

Markusen, A. (2004, November). The Work of Forgetting and Remembering Places. Urban Studies, 41(12), 23032313.

Paradigm ShiftProject. (2010). Invisible Children:TheRights of Street, Stateless+ Refugee Children. Retrieved July 20, 2010, from The Paradigm Shift Project: http://www.theparadigmshiftproject.org/malaysia-invisible_children.html

Patt, M. (2010). Street Children - Malaysia. Retrieved July 25, 2010, from Prevalence, Abuse \& Exploitation of Street Children: http://www.gvnet.com/ streetchildren/Malaysia.htm

Pica, R. (2010). More Movement, Smarter Kids. Retrieved August 15, 2010, from Moving and Learning: http://www.movingandlearning.com/Resources/

Sallis, J. F., Prochaska, J. J., \& Taylor, W. C. (1999). A Review of Correlates of Physical Activity of Children and Adolescents. Medicine \& Science in Sports \& Exercise, 32(5), 963-975.

Sandhu, I. K. (2010). Kinesthetic Learners. Retrieved August 15, 2010, from BrainyChild: http://www.brainychild.com/expert/kinesthetic-learners.shtml

Singh, J. (2007, August 6). Asia-PaciFic: Helping Malaysia's Street Children. Retrieved August 20, 2010, from AlJazeera:http://english.aljazeera.net/news/ asia-pacific/2007/07/2008525172813676892.html

Sobchack, V. (2004). The Scene of the Screen: Envisioning Cinematic and Eectronic “Presence". Retrieved July 15, 2010, from Greg Niemeyer Online Portfolio: http://studio.berkeley.edu/niemeyer/stories/seminal-essays.htm

Talen, E., \& Coffindaffer, M. (1999). The Utopianism of Children: An Empirical Study on Children's Neighbourhood Design Preferences. Journal of Planning Education and Research, 18, 321-331

Tinsley, H. E. A., Tinsley, D. J.\& Croskeys, C. E. (2002)Parkusage, social milieu, and psychosocial benefits of park use reported by older urban park users from four ethnic groups. Leisure Sciences, 24, 199-218.

Whyte, William H. (1985) The Social Life of Small Urban Space. Washington DC: The Conservation Foundation 